\title{
Sistem Informasi Geografis Pasar Tradisional di Wilayah Denpasar menggunakan Framework YII
}

\section{Geographic Information System of Traditional Market in Denpasar using YII Framework}

\author{
Luh Putu Ayu Prapitasari ${ }^{1}$, Ni Kadek Sumiari ${ }^{2}$, Ni Ketut Dewi Ari Jayanti ${ }^{3}$ \\ STMIK STIKOM Bali \\ Jl. Raya Puputan No. 86 Renon Denpasar, telp. 0361244445 \\ prapitasari@ stikom-bali.ac.id ${ }^{1}$, sumiari@ stikom-bali.ac.id ${ }^{2}$, daj@ stikom-bali.ac.id
}

\begin{abstract}
Abstrak
Pasar tradisional merupakan tempat transaksi kebutuhan pokok bagi masyarakat. Informasi lokasi pasar tradisional bagi warga masyarakat di Denpasar merupakan intrumen yang sangat penting. Sehingga perlu mengembangkan sebuah sistem yang dapat merepresentasikan lokasi atau posisi pasar tradisional tersebut. Sistem informasi geografis merupakan salah satu alternatif untuk merepresentasikan lokasi pasar tradisional. Berdasarkan hal tersebut maka pada penelitian ini bertujuan untuk membangun Sistem Informasi Geografis sebaran Pasar Tradisional di Kota Denpasar. Metode pengembangan sistem yang digunakan pada penelitian ini menggunakan pendekatan konvensional atau terstruktur. Alat yang digunakan dalam perancangan sistem adalah Data Flow Diagram dan perancangan basisdata menggunakan alat Entity Relationship Diagram. Framework yang digunakan dalam pengembangan Sistem Informasi Geografis sebaran pasar tradisional di Kota Denpasar adalah YII Framework. Pengembangan sistem diawali dengan membuat perancangan dari sistem informasi geografis sebaran pasar tradisional yaitu perancangan sistem menggunakan Data Flow Diagram (DFD) yang terdiri atas konteks diagram; perancangan basis data yang terdiri atas Entity Relationship Diagram dan konseptual basis data; serta perancangan sistem antarmuka. Hasil yang diperoleh dari penelitian ini adalah representasi informasi sebaran lokasi atau posisi pasar tradisional di Kota Denpasar.
\end{abstract}

Kata kunci: Sistem Informasi Geografis, Sebaran, Kota Denpasar, YII Framework, Pasar Tradisional

\begin{abstract}
Traditional market is a place of basic needs transaction for public citizen. The location information for the citizens of traditional market in Denpasar is a very important instrument. So the need to develop a system that can represent the location or position of the traditional markets. Geographic information system is one alternative to represent the location of traditional markets. Under these conditions, this research aims to develop a Geographic Information System distribution traditional market in Denpasar. System development method used in this study using conventional or structured approach. The tools used in the design of the system is the Data Flow Diagram and database design using Entity Relationship Diagram tools. Framework used in the development of Geographic Information Systems distribution of traditional market in Denpasar is Yii Framework. System development begins with a design of a geographic information system distribution of traditional markets, that is the system design using Data Flow Diagrams (DFD), which consists of context diagram; database design consisting of Entity Relationship Diagram and conceptual database; and system design interface. The results obtained from this study is the representation of information distribution location or position of traditional market in Denpasar.
\end{abstract}

Keywords: Geographic Information System, Distribution, Denpasar, YII Framework, Traditional Market 


\section{PENDAHULUAN}

Pasar tradisional masih merupakan wadah utama penjualan produk-produk kebutuhan pokok yang dihasilkan oleh para pelaku ekonomi bersekala menengah kecil serta mikro. Kebutuhan informasi pasar tradisional bagi masyarakat di Kota Denpasar merupakan intrumen yang sangat penting mengingat sangat minimnya informasi tentang pasar tradisional seperti informasi lokasi pasar, komoditas pasar dan informasi-informasi lainnya yang bermanfaat bagi masyarakat.

Kota Denpasar merupakan kota yang memiliki komoditas pasar yang sangat menjanjikan karena padatnya penduduk dan banyaknya kebutuhan masyarakat akan produk-produk pasar. Menurut data tahun 2013 dari Dinas Perindustrian dan Perdagangan Kota Denpasar jumlah pasar tradisional yang ada di Kota Denpasar 16 pasar tradisional yang tersebar di seluruh wilayah kota Denpasar. Pasar tradisional tersebut terdiri dari 2 kategori yaitu pasar ikan dan pasar adat.[1] Namun meskipun merupakan kota besar keberadaan pasar tradisional di Kota Denpasar mulai tersisih. Salah satu permasalahannya adalah letak lokasi pasar tradisional yang biasanya terletak di lokasi-lokasi terpencil sehingga susah untuk dicari. Selain itu pengumpulan dan penyimpanan data pasar tradisional yang dilakukan pemerintah masih bersifat manual yaitu dengan melakukan pendataan langsung ke lokasi dan penyimpanan data menggunakan document hardcopy sehingga menyita banyak tempat, waktu dan data yang ada belum valid. Perkembangan teknologi informasi seperti yang kita ketahui saat ini sangat berkembang pesat. Akan sangat bermanfaat apabila pemerintah kota Denpasar bisa memanfaatkan teknologi infromasi yang ada saat ini untuk menunjang kebutuhan data dan infromasi pasar tradisional di wilayah kota Denpasar. Apabila teknologi informasi bias dimanfaatkan dengan baik dalam pengolahan data dan informasi pasar tradisional di kota Denpasar, data yang informasi yang diperoleh akan lebih valid, menghemat biaya dan tempat serta tidak terlalu banyak menyita waktu. Oleh karena latarbelakang di atas dalam penelitian ini penulis memberikan solusi untuk pengolahan data dan infromasi pasar tradisional di kota Denpasar yaitu dengan membangun sebuah Sistem Informasi Geografis (SIG) berbasis web dimana dalam system tersebut selain terdapat informasi lokasi pasar juga informasi-informasi penting yang berkaitan dengan pasar tradisional yang ada di wilayah kota Denpasar.

Sistem Informasi Geografis merupakan sejenis perangkat lunak yang dapat digunakan untuk pemasukan, penyimpanan, manipulasi, menampilkan, dan keluaran informasi geografis berikut atribut-atributnya [2]. SIG dapat diuraikan menjadi beberapa sub sistem [2], yaitu: (1) Data Input: mengumpulkan dan mempersiapkan data spasial dan atribut dari berbagai sumber. Sub sistem ini pula bertanggung jawab dalam mengkonversi atau mentranformasikan formatformat yang dapat digunakan oleh Sistem Informasi Geografis. (2) Data Output : menampilkan atau menghasilkan keluaran seluruh atau sebagian basis data baik dalam bentuk softcopy maupun dalam bentuk hardcopy seperti tabel, grafik, peta, dan lain-lain. (3) Data Management : mengorganisasikan baik data spasial maupun atribut ke dalam sebuah basis data sedemikian rupa sehingga mudah dipanggil, diperbaharui, dan diperbaiki. (4) Data Manipulation and Analysis : menentukan informasi-informasi yang dapat dihasilkan oleh SIG. Selain itu, sub sistem ini juga melakukan manipulasi dan pemodelan data untuk menghasilkan informasi yang diharapkan.

Ada beberapa penelitian terdahulu tentang Sistem Infromasi Geografis, diantaranya adalah Sistem Informasi Geografis Untuk Perjalanan Wisata di kota Semarang oleh Danny Manongga dkk. Pada penelitian ini mengangkat permasalahan tentang penyediaan informasi dari buku panduan dan peta membantu pencarian lokasi atau rute yang perlu ditempuh dan membantu mencari lokasi tempat wisata di Kota Semarang. Sistem Informasi Geografis yang dibangun menyediakan informasi seperti hotel, restoran, tempat wisata, bank dan lainnya, jalan yang menghubungkan tempat-tempat tersebut, maupun deskripsi tentang tempat dan jalan. Sistem diimplementasikan di kota Semarang, dengan menyediakan tools untuk searching dan informasi tentang fasilitas wisata beserta foto untuk wisatawan. Dengan kemampuan SIG, wisatawan mempunyai panduan untuk membantu perjalanan di Semarang [3]. Penelitian selanjutnya adalah 
dari Pratomo Setiaji yaitu Sistem Informasi Geografis Industri di Kabupaten Kudus. Hasil dari penelitian ini adalah Sistem Informasi Geografis yang dapat membantu mengetahui titik letak industri di kabupaten Kudus. Sistem Informasi Geografis ini dirancang dengan menggunakan pemodelan dengan UML Sedangkan pemrograman yang digunakan adalah Quatum GIS dan Map Server dan menghasilkan Sistem Informasi Geografis untuk Mengetahui lokasi industri di Kabupaten Kudus. [4] Pada penelitian yang dilakukan oleh Sandy Kosasi yang berjudul Perancangan Sistem Informasi Geografis Mendirikan Stasiun Pengisian Bahan Bakar Umum dimana tujuan dari penelitian tersebut adalah menghasilkan sistem informasi geografis berbasis web untuk memberikan kemudahan mengetahui kondisi lahan dan lokasi baru untuk mendirikan SPBU, tanpa harus melalui tahap survei terlebih dulu. Metode pengembangan sistem perangkat lunak menggunakan model Waterfall Model. Dalam pembuatannya menggunakan peta online yang disediakan oleh Google Maps. Sistem informasi geografis dapat memberikan informasi yang akurat tentang persebaran lokasi secara spasial dan non-spasial yang lebih informatif di Kecamatan Pontianak Selatan. Sistem ini juga berisi informasi tentang lokasi spasial SPBU, alamat SPBU, fasilitas SPBU dan pemetaan lokasi kebutuhan membangun sebuah SPBU baru.[5]

Berdasarkan latar belakang dan penelitian-penelitian terkait sebelumnya maka dalam penelitian ini akan dibangun Sistem Informasi Georafis Pasar Tradisional di Wilayah Denpasar. Metode pengembangan sistem yang digunakan pada penelitian ini menggunakan pendekatan konvensional atau terstruktur yaitu menggunakan tools Data Flow Diagram (DFD) dan Entity Relationship Diagram (ERD) untuk perancangan databasenya. Untuk membangun Sistem Informasi Geografis Pasar Tradisional di Wilayah Denpasar berbasis web menggunakan YII framework. "Yii adalah framework (kerangka kerja) PHP berbasis-komponen, berkinerja tinggi untuk pengembangan aplikasi Web berskala-besar. Yii menyediakan reusability maksimum dalam pemrograman Web dan mampu meningkatkan kecepatan pengembangan secara signifikan. YII Framework menggunakan struktur model view dan control (MVC) dalam struktur websitenya sehingga mempermudah dalam pengembangan website. Penelitian ini menghasilkan sistem informasi geografis pasar tradisional di daerah Denpasar menggunakan YII Framework [6]. Sistem ini nantinya bisa membantu dalam sebaran lokasi pasar tradisional khususnya di Kota Denpasar.

\section{METODE PENELITIAN}

Tahap pertama yang dilakukan dalam penelitian ini adalah melakukan pengumpulan data yang diperlukan selama penelitian. Teknik pengumpulan data yang dilakukan dalam penelitian ini adalah observasi dimana pengamatan dan pencatatan secara sistimatik terhadap unsur-unsur yang tampak dalam suatu gejala atau gejala-gejala dalam objek penelitian. Tujuan observasi adalah mendeskripsikan setting yang dipelajari, aktivitas-aktivitas yang berlangsung, orangorang yang terlibat dalam aktivitas, dan makna kejadian di lihat dari perspektif mereka yang terlihat dalam kejadian yang diamati tersebut. Observasi dalam penelitian ini dilakukan melalui pengamatan terhadap system pasar yang sudah ada di kota lain.

Teknik wawancara juga dilakukan, dimana data yang dihasilkan dari wawancara dapat dikategorikan sebagai sumber primer karena didapatkan langsung dari sumber pertama. Proses wawancara dilakukan dengan mengajukan pertanyaan kepada narasumber atau responden tertentu [7]. Dalam kasus wawancara dilakukan dengan pengelola pasar traditional di Kota Denpasar yaitu pihak Dinas Perindustrian dan Perdagangan Kota Denpasar. Teknik lain yang dilakukan adalah studi literatur, yang diperoleh dari sumber-sumber pustaka seperti majalah, internet dan buku refrensi atu dokumen-dokumen tertentu yang berhubungan dengan sistem informasi berbasis web. Sumber-sumber pustaka inilah yang penyusun harapkan dapat menjadi acuan untuk melakukan penelitian ini dan dapat mengambil suatu kesimpulan untuk suatu hal yang akan dicari. Berikut merupakan detail alur penelitian yang dilakukan. 


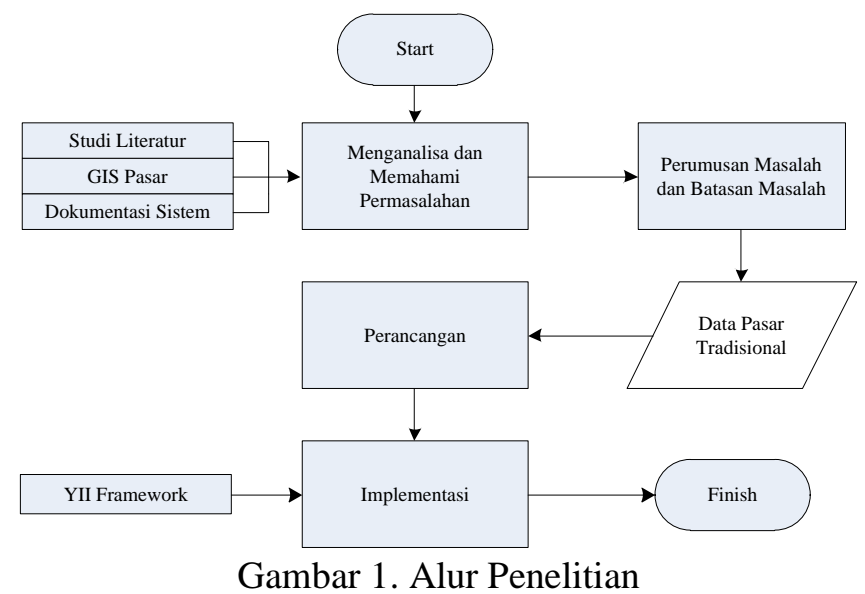

\section{HASIL DAN PEMBAHASAN}

Pada bagian ini dibahas mengenai analisa kebutuhan dari sistem yang dibangun. Berdasarkan analisa yang dihasilkan, dilanjutkan dengan melakukan perancangan yang teridiri atas perancangan sistem, perancangan basis data serta perancangan antarmuka sistem. Terakhir implementasi sistem dan menyajikan screenshoot sistem informasi geografis sebaran pasar tradisional di kota Denpasar.

\subsection{Analisa Kebutuhan}

Analisa kebutuhan merupakan tahap menganalisa semua kebutuhan yang diperlukan dalam membangun system ini berdasarkan masalah yang telah dipaparkan pada rumusan dan batasan masalah. Analisis ini mencakup kebutuhan secara fungsional maupun yang non fungsional[8]. Sistem ini dibangun dengan tujuan untuk membantu Dinas Perindustrian dan Perdagangan Kota Denpasar untuk medata pasar tradisional yang ada di wilayah denpasar. Sistem ini dibangun dengan tampilan yang mudah digunakan oleh pengguna dengan diberikan petunjuk penggunaan agar user yang menggunakannya merasa nyaman dan mudah menggunakannya. Analisa kebutuhan fungsional ini merupakan analisa kebutuhan-kebutuhan fungsional dari perangkat lunak yang dibuat. Kebutuhan fungsional ini merupakan fitur-fitur yang terdapat pada perangkat lunak yang dibuat. Hal ini dibutuhkan agar tidak semua pengguna sistem bisa melakukan semua fungsi-fungsi yang terdapat dalam sistem ini. Ada beberapa fungsi yang hanya pengguna dengan level tertinggi yang bisa dilakukan yaitu fungsi maintanance. Berdasarkan kebutuhan ini, terdapat dua level user, yaitu Admin dan user. Fungsi yang bisa dilakukan oleh Admin pada sistem ini yaitu (1) Login, dan (2) Maintanance Data. Sedangkan fungsi yang bisa dilakukan oleh user adalah (1) Melihat data pasar dan (2) Mengirim pesan.

\subsection{Perancangan}

Perancangan yang dilakukan pada penelitian ini adalah perancangan sistem, perancangan basis data serta perancangan antarmuka sistem. Berikut pemaparan dari perancangan yang dilakukan.

\subsubsection{Perancangan Sistem}

Pada tahapan ini dilakukan sebuah perancangan sistem didasarkan atas hasil analisa kebutuhan yang telah dibahas sebelumnya. Perancangan sistem dirancang untuk mengetahui alur serta proses data yang terjadi di dalam sistem yang akan dibuat[7]. Pada tahap ini akan dilakukan perancangan sistem yang akan dibangun dengan menggunakan Data Flow Diagram (DFD).

Diagram Konteks menggambarkan sistem secara umum dimana terdiri dari 2 eksternal entity yang menggunakan sistem ini yaitu Admin dan User. Seperti yang dapat dilihat dari diagram konteks berikut, Admin memiliki 6 arus data input dan 7 arus data output yaitu :

Arus Data Input : Data_login

Data_kategori 
Data_omset

Data_statis

Data_user

Data_Pasar

Arus Data Output: Info_Kategori

Info_omset

Info_dt_pasar

Info_data_login

Info_dt_user

Info_dt_pesan

Info_dt_statis

Sedangkan untuk User 1 arus data input yaitu data_pesan dan 4 arus data output yaitu info_data_statis, Info_data_kategori, info_data_pasar, info_data_omset.

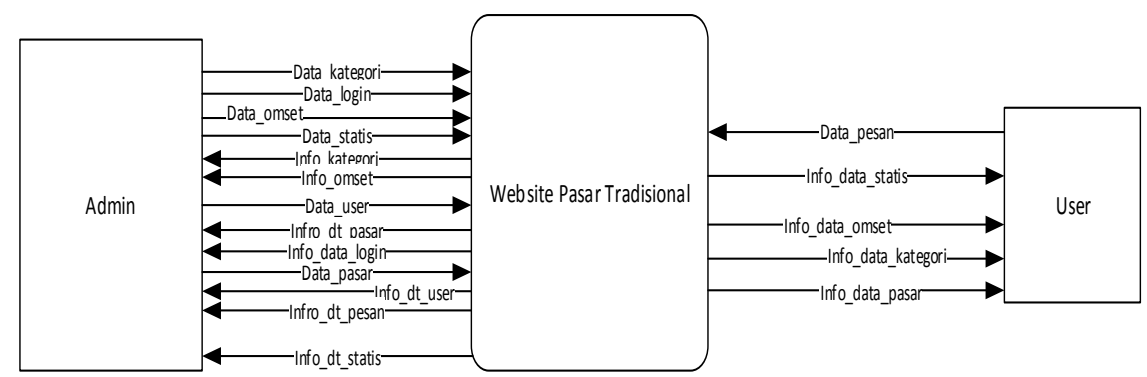

Gambar 2. Diagram Konteks

Berdasarkan diagram konteks tersebut, maka proses dipecah ke dalam dua proses yaitu proses login dan proses maintanance data. Proses login melibatkan eksternal entity admin dan data store yang terlibat adalah user Proses maintanance data melibatkan eksternal entity Admin dan User, dan ada 6 data store yang terlibat yaitu : statispage, kategoripasar, pasar, foto, omset_pasar, dan pesan

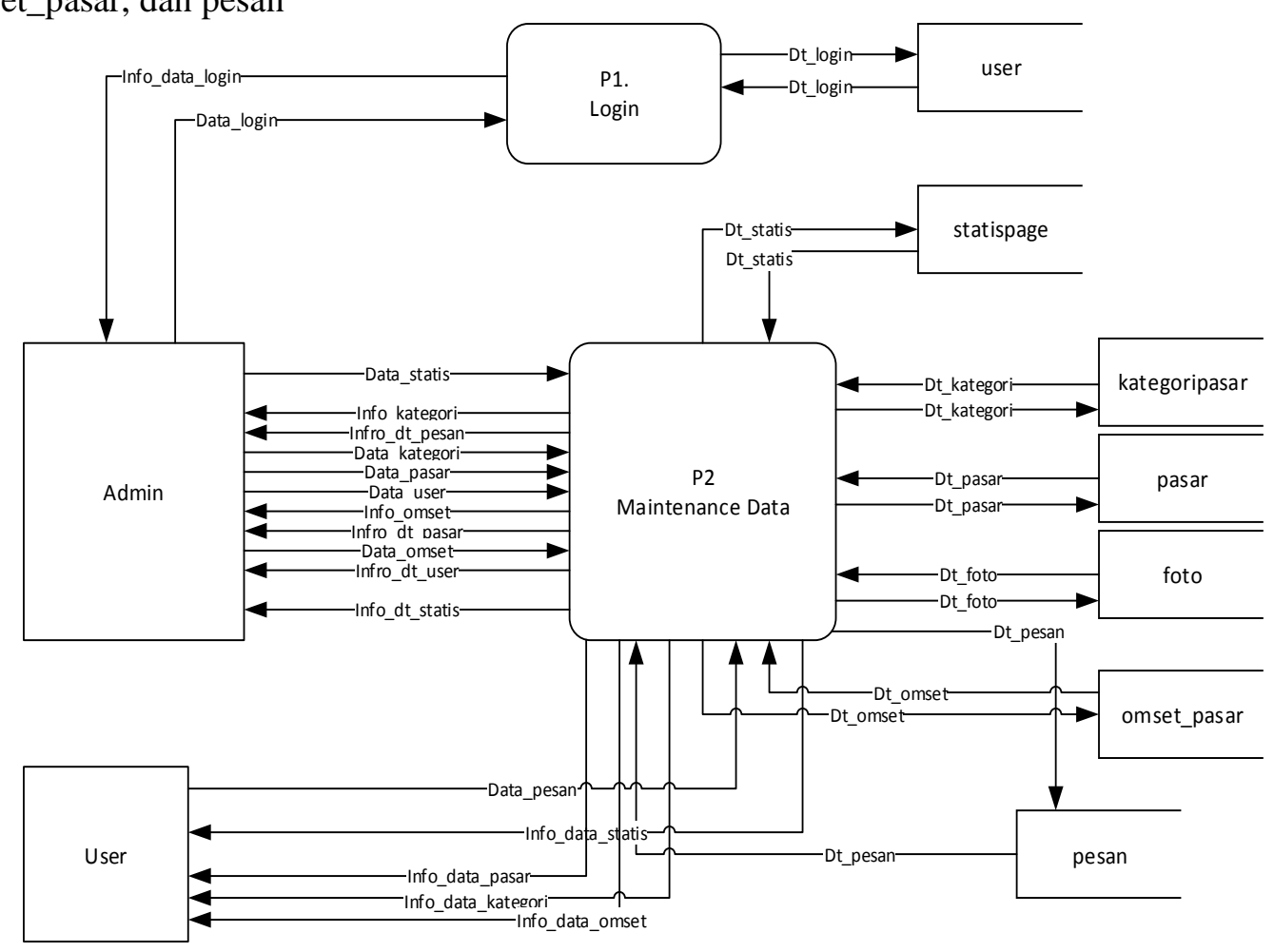

Gambar 3. Level 1 


\subsubsection{Perancangan Basis Data}

Perancangan basis data dirancang untuk mengetahui relasi data yang terjadi di dalam sistem yang akan dibuat. Pada tahap ini akan dilakukan perancangan basis data menggunakan Entity Relationship Diagram (ERD) dan Konseptual Basis Data .

Entity Relationship Diagram (ERD) pada Sistem Informasi Geografis Pasar Tradisional Di Wilayah Denpasar Berbasis Web menggambarkan relasi data yang terjadi antar entitas. Pada ERD ini terdapat 4 entitas, dimana tidak semua entitas saling berelasi. Adapun 4 entitas tersebut adalah sebagai berikut :

a. Entitas Kategoripasar : menyimpan data kategori pasar

b. Entitas Pasar : menyimpan data pasar

c. Entitas Foto : menyimpan data foto

d. Entitas Omset_pasar : menyimpan data omset pasar

Sedangkan relasi yang dijabarkan sebagai berikut:

a. Entitas kategoripasar berelasi dengan entitas pasar dengan cardinality ratio constraint 1 : $\mathrm{N}$, dimana 1 kategori pasar memiliki banyak pasar.

b. Entitas Pasar berelasi dengan entitas Foto dengan cardinality ratio constraint 1 : N, dimana 1 pasar memiliki banyak foto

c. Entitas Pasar berelasi dengan entitas Omset_Pasar dengan cardinality ratio constraint 1 : $\mathrm{N}$, dimana 1 Pasar memiliki banyak Omset Pasar

Berikut Entity Relationship Diagram (ERD) pada Sistem Informasi Geografis Pasar Tradisional Di Wilayah Denpasar Berbasis Web

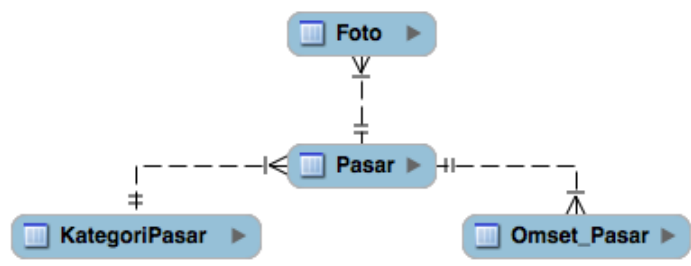

\section{Gambar 4. Entity Relationship Diagram}

Konseptual basis data merupakan pengembangan dari Entity Relationship Diagram (ERD) dan pada konseptual basis data menggambarkan bagaimana entitas berelasi dan atribut yang merelasikan entitas tersebut. Berikut merupakan gambaran konseptual basis data Sistem Informasi Geografis Pasar Tradisional Di Wilayah Denpasar Berbasis Web

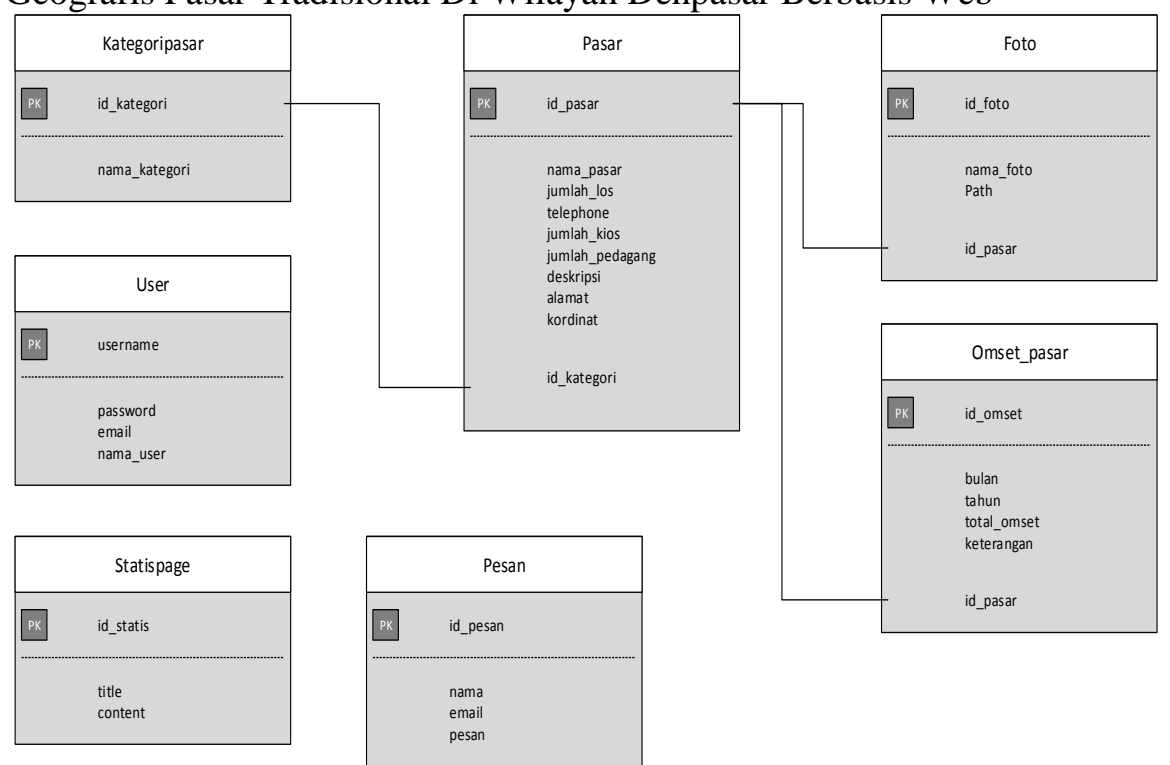

Gambar 5. Konseptual Basis Data 


\subsubsection{Perancangan Antarmuka Sistem}

\section{A. Halaman Utama}

Halaman ini merupakan halaman utama dari system yaitu halaman yang pertama kali muncul ketika sistem diakses

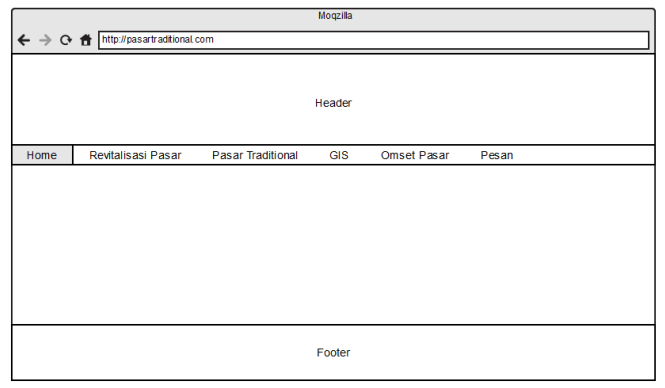

Gambar 6. Halaman Utama

B. Halaman Pasar

Halaman ini merupakan halaman untuk menampilkan data list pasar tradisional yang ada di daerah Denpasar

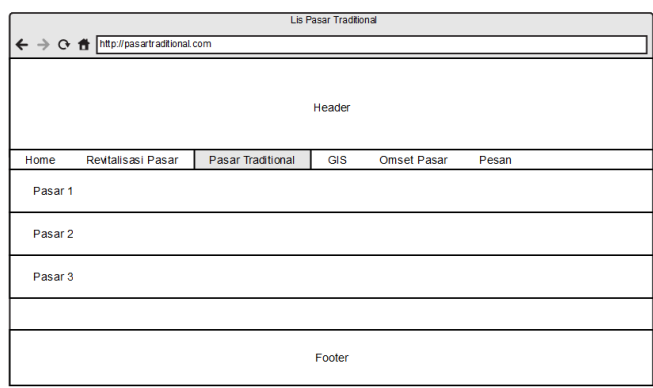

Gambar 7. Halaman Pasar

C. Halaman Detail Pasar

Halaman ini merupakan halaman untuk menampilkan detail pasar tradisional dimana berisikan data-data dari pasar dan peta lokasi pasar

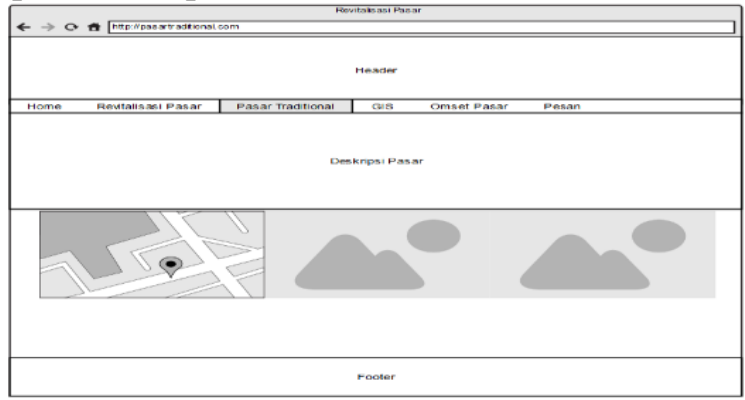

Gambar 8. Halaman Detail Pasar

D. Halaman GIS

Halaman ini digunakan untuk menampilkan peta lokasi pasar traditional di daerah Denpasar secara menyeluruh.

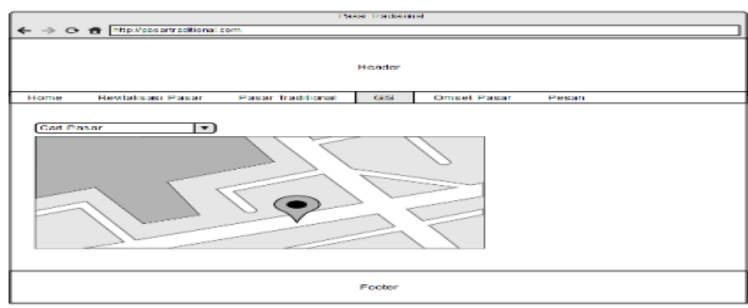

Gambar 9. Halaman Sistem Informasi Geografis (SIG) 


\section{E. Halaman Admin Kategori}

Halaman ini digunakan untuk melakukan maintenance data kategori dari website, diaman pada halaman ini terdapat kategori yang sudah tersedia serta button untuk melakukan input, update dan delete

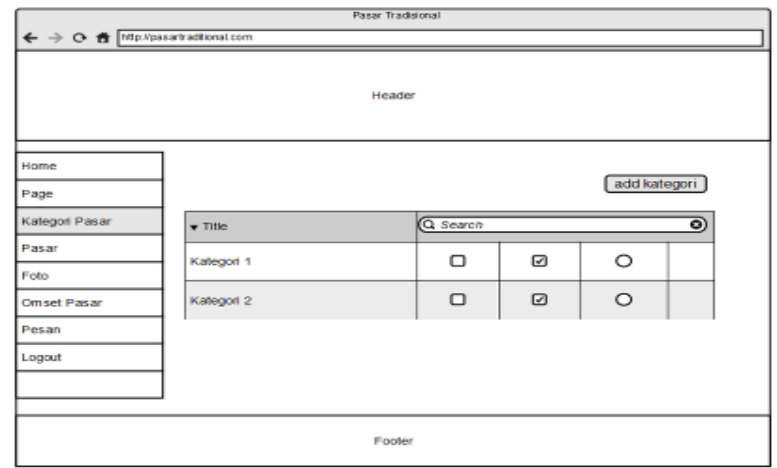

Gambar 10. Halaman Maintenance Kategori

F. Halaman Maintenance Pasar

Halaman ini digunakan untuk melakukan maintenance data statis pasar website, diaman pada halaman ini terdapat list pasar yang sudah tersedia serta button untuk melakukan input, update dan delete

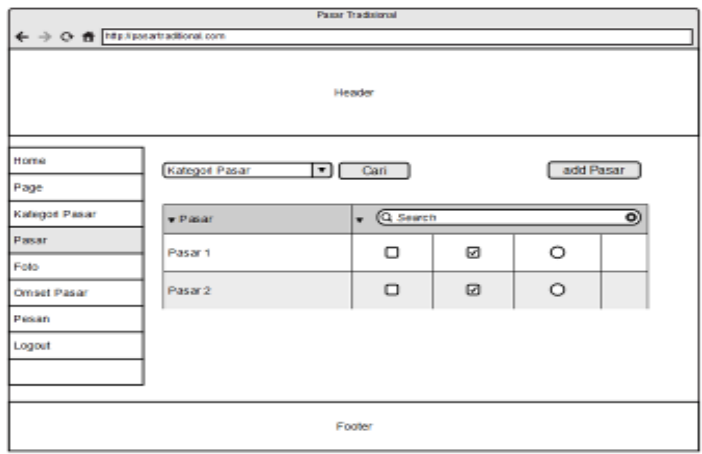

Gambar 11. Maintenance Data Pasar

G. Halaman Maintenance Pesan

Halaman ini digunakan untuk melakukan maintenance data pesan dari website, diaman pada halaman ini terdapat list pesan yang sudah ada serta button untuk melakukan update dan delete

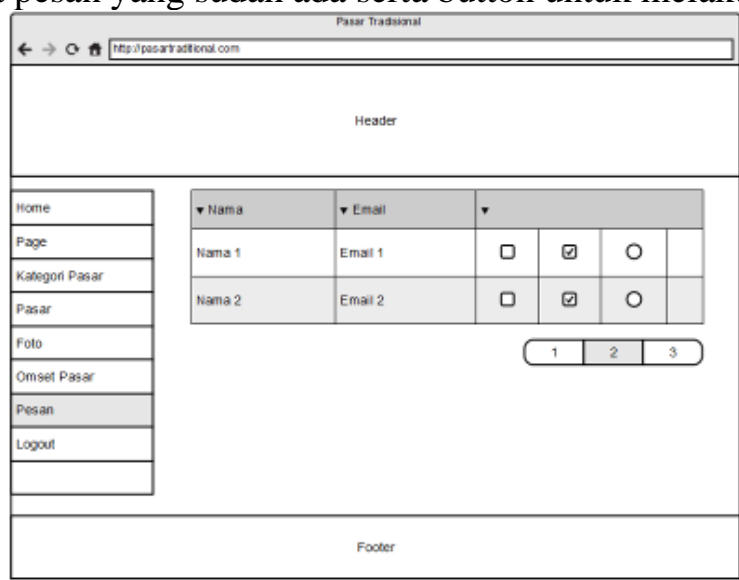

Gambar 12. Halaman Maintenance Data Pesan 


\subsection{Implementasi Sistem}

Hasil implementasi sistem disajikan berdasarkan pengguna sistem yaitu user dan admin. Berikut penjabarannya.

\subsubsection{Hak Akses User}

A. Halaman Utama

Tampilan halaman utama merupakan halaman yang muncul saat user mengakses sistem pertama kasli

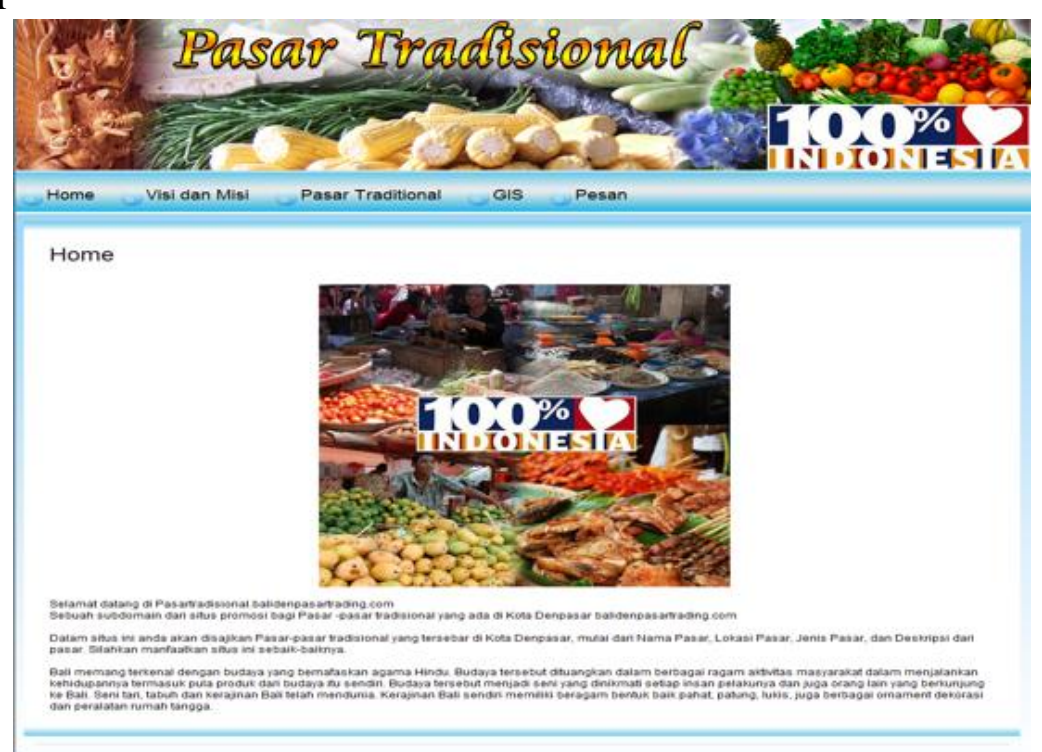

Gambar 13. Tampilan Halaman Utama Sistem

B. Halaman Pasar Tradisional

Pada laman ini user dapat melihat informasi pasar tradiosional yang memuat nama pasar, alamat pasar, koordinat lokasi pasar, telepon, jumlah los dan jumlah kios. Pada nama pasar terdapat tautan yang menuju pada detail pasar yang dituju serta peta lokasi pasar.

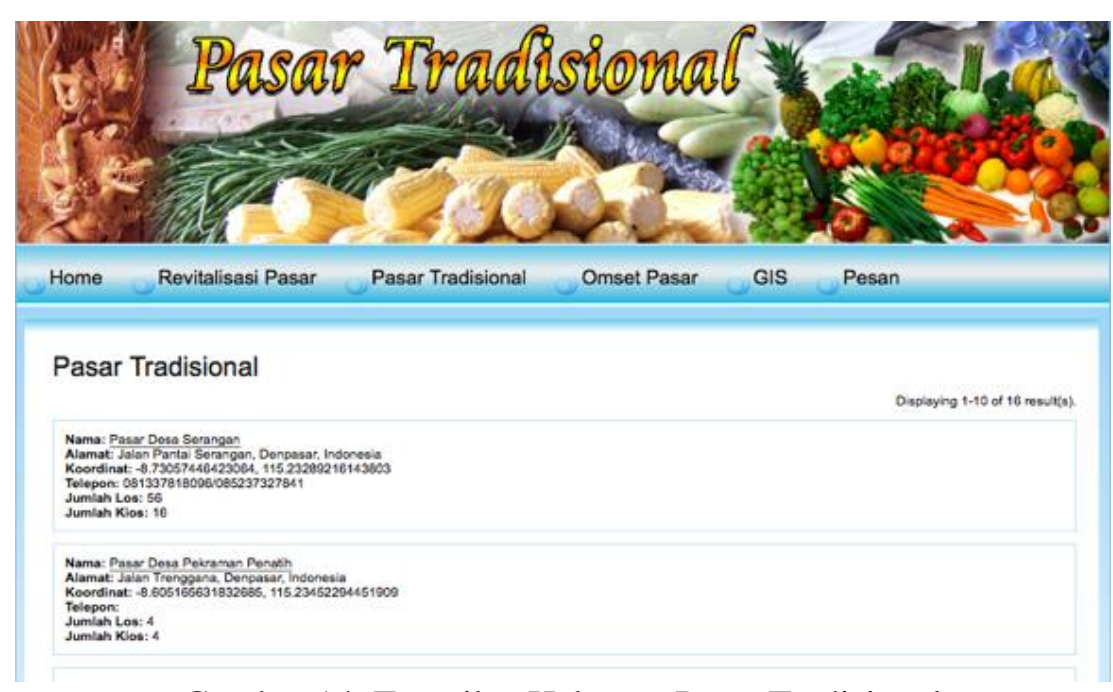

Gambar 14. Tampilan Halaman Pasar Tradisional 


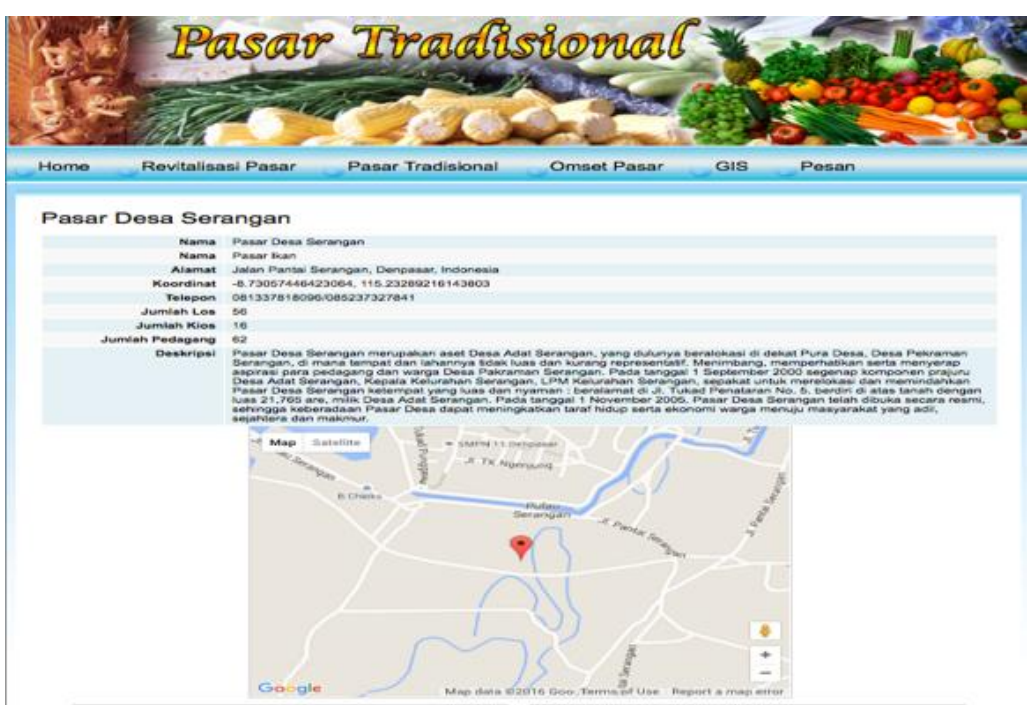

Gambar 15. Tampilan Halaman Detail Pasar Tradiosional

\section{Halaman GIS}

Laman ini merupakan laman Map/Peta lokasi-lokasi pasar yang ada di Denpasar. User bisa mecari lokasi pasar dengan menggeser "Kursor" pada Peta. Ketika lokasi pasar sudah ditemukan maka informasi pasar bisa langsung diketahui yaitu nama pasar dan alamat pasar. Selain itu bisa dipilih dari pencarian cepat nama pasar. Apabila ingin mengetahui detail dari pasar bisa meng Klik "Rincian", maka akan muncul laman Detail Pasar.

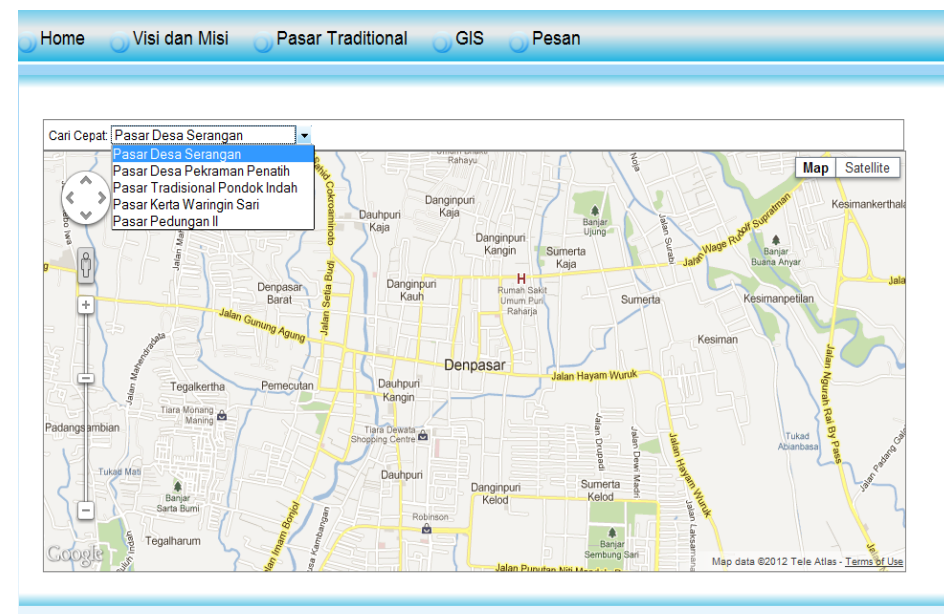

Gambar 16. Tampilan Halaman GIS 


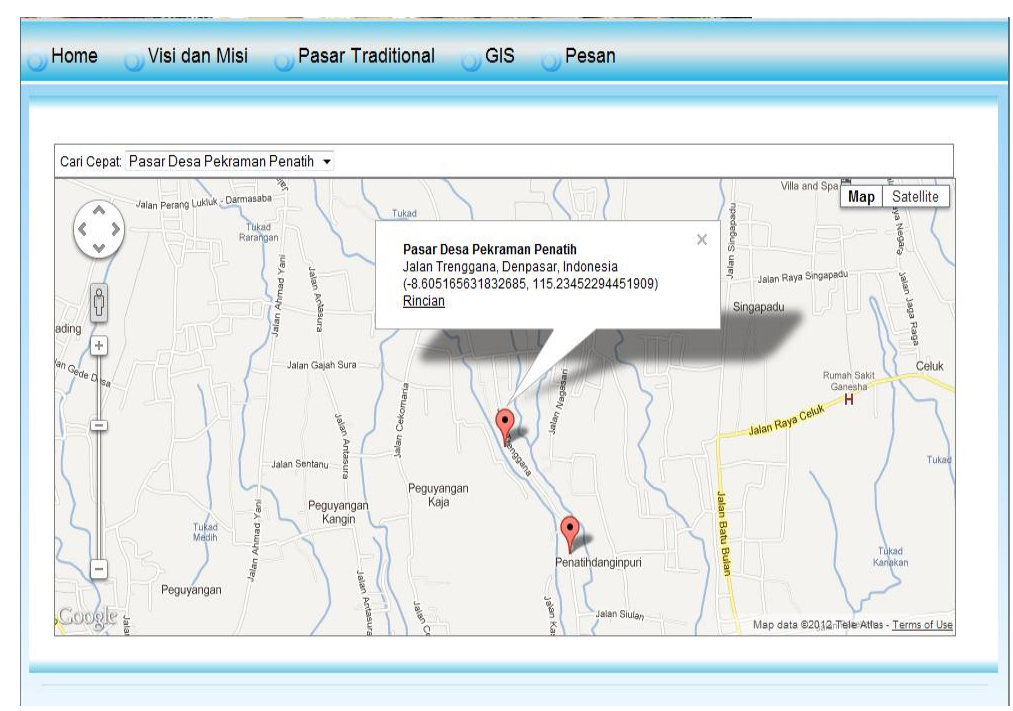

Gambar 17. Tampilan Halaman Detail GIS

\subsubsection{Hak Akses Admin}

\section{A. Halaman Kelola Pasar Tradisional}

Laman ini digunakan untuk mengelola data pasar seperti melihat list pasar, menambahkan kategori pasar, mengupdate atau mengubah kategori pasar, dan juga mengahpus kategori pasar.

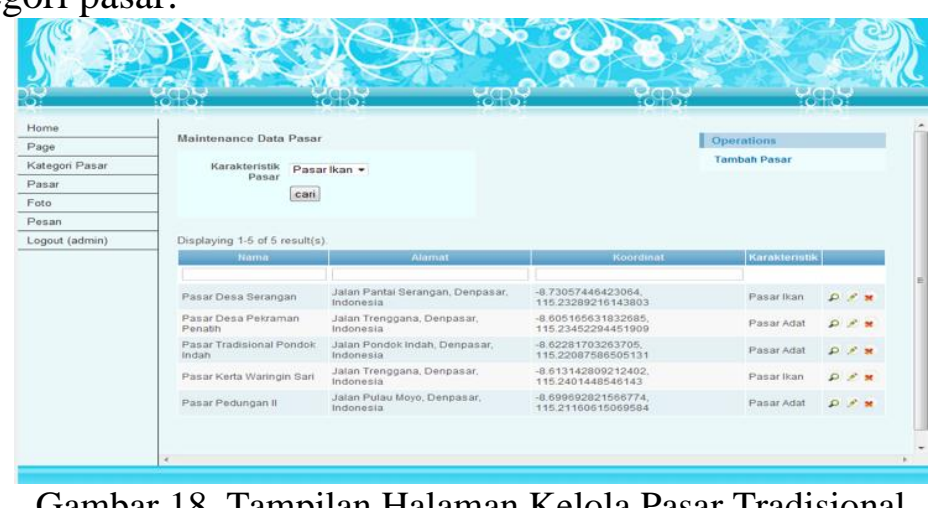

\section{B. Halaman Kelola Pesan}

Pada laman pesan ini admin bisa melihat pesan yang di inputkan oleh pengunjung di laman utama "Pesan". Admin hanya bisa melihat pesan. Dan untuk membalasnya admin bisa mengirimkan langsung pesan ke email dari si pengirim pesan.

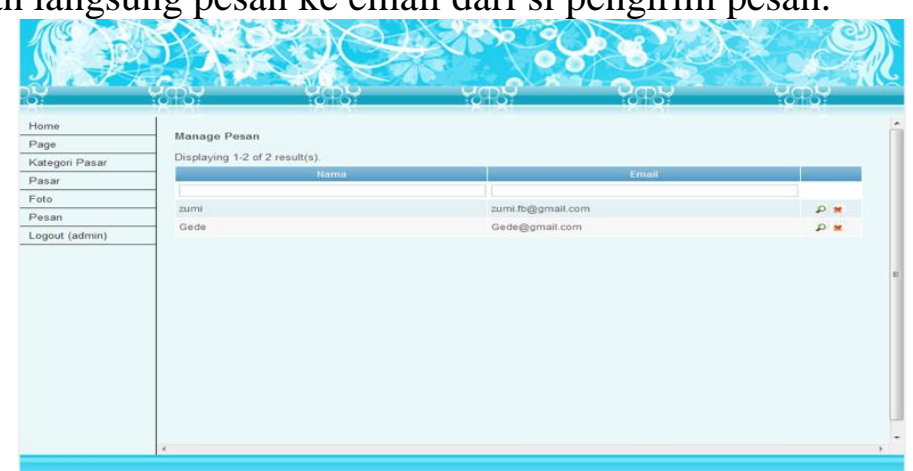

Gambar 19. Tampilan Halaman Kelola Pesan 


\section{KESIMPULAN}

Kesimpulan yang dapat diambil dari penelitian ini adalah berhasil dikembangkannya sistem informasi geografis sebaran lokasi pasar tradisional di Denpasar berdasarkan kebutuhan fungsional yang telah ditetapkan dengan menggunakan framework YII. Pengembangan sistem yang dilakukan menggunakan kaidah pendekatan konvensional atau terstruktur dalam pengembangan perangkat lunak yaitu membuat perancangan sistem menggunakan Data Flow Diagram (DFD) yang terdiri atas konteks diagram dan level 1; perancangan basis data yang terdiri atas Entity Relationship Diagram dan konseptual basis data; serta perancangan antarmuka sistem. Hasil yang diperoleh dari penelitian ini adalah representasi informasi pemetaan lokasi atau posisi pasar tradisional di Kota Denpasar.

\section{SARAN}

Saran yang dapat diberikan guna pengembangan penelitian ini adalah menyempurnakan penelitian ini dengan menambahkan fungsi pencarian lokasi pasar tradisional dengan menerapkan algoritma pencarian jarak terdekat seperti algoritma floyd warshall.

\section{UCAPAN TERIMA KASIH}

Penulis mengucapkan terima kasih kepada STMIK STIKOM Bali yang telah memberi dukungan financial terhadap penelitian ini.

\section{DAFTAR PUSTAKA}

[1.] Walikota Denpasar. 2009. Peraturan Walikota Denpasar Nomor 9 Tahun 2009 Tentang Penataan Dan Pembinaan Pasar Tradisional, Pusat Perbelanjaan, Dan Toko Modern Pasal 1. Walikota Denpasar : Denpasar

[2.] Prahasta,Eddy. 2005. Konsep-Konsep Dasar Sistem Informasi Geografis. Informatika: Bandung

[3.] Manongga Danny, Samuel Papilaya, Selfiana Pandie. 2009. Sistem Informasi Geografis Untuk Perjalanan Wisata Di Kota Semarang. Jurnal Informatika. Vol. 10, No. 1, Mei 2009:

[4.] Setiaji Pratomo. 2012. Sistem Informasi Geografis Industri Di Kabupaten Kudus. Seminar Nasional Teknologi Informasi \& Komunikasi Terapan 2012 (Semantik 2012) : Semarang

[5.] Kosasi, Sandy. 2015. Perancangan Sistem Informasi Geografis Mendirikan Stasiun Pengisian Bahan Bakar Umum. CSRID Journal, Vol.7 No.3 Oktober 2015, Hal. 167-178

[6.] Sabit Huraira. 2012. Menjelajah Yii Framework. Ebook

[7.] Dewi Ari Jayanti, Ni Ketut. 2013. Analisa Dan Perancangan Sistem Informasi Penentuan Kompetensi Mahasiswa. Penelitian Internal Periode 2 STMIK STIKOM Bali

[8.] Jogiyanto. 2005. Analisa dan Desain Sistem. Yogyakarta: ANDI. 